Visserman, M. L, Righetti, F., Kumashiro, M., \& Van Lange, P. A. M. (online publication, $30^{\text {th }}$ August, 2016). Me or us? Self-control promotes a healthy balance between personal and relationship concerns. Social Psychological and Personality Science, 111. DOI: $10.1177 / 1948550616662121$

Pre-Print Version: Accepted for publication at Social Psychological and Personality Science. Please do not distribute without permission.

Me or Us? Self-Control Promotes a Healthy Balance between

Personal and Relationship Concerns

\author{
Mariko L. Visserman \\ VU Amsterdam \\ Francesca Righetti \\ VU Amsterdam \\ Madoka Kumashiro \\ Goldsmiths, University of London \\ Paul A. M. van Lange \\ VU Amsterdam
}

Corresponding author: Mariko L. Visserman, Department of Experimental and Applied Psychology, VU Amsterdam, van der Boechorststraat 1, 1081 BT Amsterdam, the Netherlands. Email: m.l.visserman@vu.nl 


\begin{abstract}
Although romantic partners strive to achieve an optimal balance in fulfilling both personal and relational concerns, they are inevitably challenged by how much time and effort they can dedicate to both concerns. In the present work, we examined the role of self-control in successfully maintaining personal-relational balance, through promoting balance and preventing personal and relational imbalance (overdedication to personal or relational concerns, respectively). We conducted two studies among romantic couples (total $N=555$ ), using questionnaires and diary procedures to assess everyday experiences of personalrelational balance and imbalance. Findings from both studies consistently showed that selfcontrol promotes personal-relational balance. Moreover, findings partly supported our hypothesis that self-control prevents personal and relational imbalance (Study 2). Finally, findings also revealed that maintaining personal-relational balance is one of the mechanisms by which self-control can promote personal and relationship well-being. Implications of the present findings and avenues for future research are discussed.
\end{abstract}

Keywords: Romantic relationships, self-control, personal-relational balance, personal well-being, relationship well-being 


\section{Me or Us? Self-Control Promotes a Healthy Balance between Personal and Relationship Concerns}

Pro-relationship behaviors, such as sacrificing one's own interests and accommodating a partner's transgressions promote the stability, vitality, and ultimately the longevity of a romantic relationship (e.g., Rusbult, Verette, Whitney, Slovik, \& Lipkus, 1991; Van Lange et al., 1997). Clearly, this is an important insight, because relationships are a substantial source of people's well-being (e.g., Kamp Dush \& Amato, 2005; Kiecolt-Glaser \& Newton, 2001). But is it really true that higher levels of pro-relational dedication unequivocally promote the well-being of a relationship, and consequently, one's own well-being? Some previous studies suggest that there is something as "too much" relationship dedication, such as when people are too forgiving (Luchies, Finkel, McNulty, \& Kumashiro, 2010), immerse themselves too much in the relationship (Helgeson \& Fritz, 1998), or silence their own opinions (Harper \& Welsh, 2007), illustrating that relationship dedication can at times come at the expense of one's own needs. Similarly, people can immerse themselves too much in their personal goals and needs, at the expense of their relationship. Instead of (overly) dedicating to the relationship — or to personal goals — we argue that key to personal and relationship well-being lies in successfully balancing dedication to personal and relational concerns.

Our theoretical perspective focuses on two propositions. First, we propose that people are driven by strong motives to satisfy both sets of goals and needs (Deci \& Ryan, 2000) but that successfully maintaining personal-relational balance can be challenging, given the limited amount of time and energy that are available to invest in both concerns (Kumashiro, Rusbult, \& Finkel, 2008). Moreover, individuals may differ in their ability to achieve such balance on a regular basis. In the present work, we propose self-control as a key factor that enables people to sustain the balance between personal and relational concerns. Second, we propose that the ability to successfully maintain personal-relational balance is one of the reasons why 
self-control promotes personal and relational well-being (e.g., Hofmann, Luhmann, Fisher, Vohs, \& Baumeister, 2014; Vohs, Finkenauer, \& Baumeister, 2011).

\section{Personal-relational balance}

The optimal level of balance ${ }^{1}$ between personal and relational concerns can vary across people. Some individuals may place more importance on personal concerns (e.g., having a successful career), while others prefer to spend time and energy on their relational concerns (Kumashiro et al., 2008). In either case, individuals are likely to face situations of imbalance in their preferred dedication to either set of concerns. Personal imbalance results from a subjective feeling that the individual is overdedicating to personal concerns at the expense of relational concerns. For example, people may feel that they are spending too much time and effort on their own goals and are neglecting their partner. Relational imbalance results from a subjective feeling that the individual is overly dedicating to relational concerns at the expense of personal concerns. This might occur when people feel that they are giving too much to the relationship (e.g., spending too much time with their partner, accommodating, sacrificing or forgiving too much) and are neglecting their personal goals and needs. In contrast, personal-relational balance occurs when an individual feels right about the amount of time and resources that (s)he is dedicating to both personal and relational concerns (Kumashiro et al., 2008). Importantly, these perceptions may be independent from the actual time, effort and resources that are spent toward relational or personal goals.

Previous research has shown that experiencing imbalance over time-whether at the costs of personal or relational concerns - has detrimental consequences for one's personal well-being and one's relationship (Kumashiro et al., 2008). In contrast, maintaining an optimal personal-relational balance is associated with high levels of both personal and relationship well-being (Kumashiro et al., 2008; Patrick, Knee, Canevello, \& Lonsbary, 2007). However, achieving and maintaining an optimal personal-relational balance can be 
challenging: relationship partners can find themselves neglecting each other for a long time because of being overinvolved with their career's goals, or partners can become overly dedicated to their relationship and neglect their hobbies or their career opportunities.

\section{Self-control}

Given that individuals typically strongly desire to fulfill important needs and goals in both the personal and relational domains (Aron \& Aron, 1986; Baumeister \& Leary, 1995; Deci \& Ryan, 2000), they are likely to hold a long-term goal of achieving personal-relational balance. In the present research, we propose that to successfully balance personal and relational concerns, people need to have the ability to maintain personal-relational balance and prevent personal and relational imbalance. Specifically, we argue that self-control provides such ability because self-control is the ability to direct thoughts, motivations, and behaviors in a goal-directed manner (Baumeister, Heatherton, \& Tice, 1994). Self-control enables the inhibition of undesired responses, and promotes behaviors that are in accordance with one's (long-term) standards (Baumeister, Vohs, \& Tice, 2007; Hofmann, Schmeichel, \& Baddeley, 2012). Accordingly, self-control may help individuals to achieve personalrelational balance (i.e., their preferred level of dedication to both concerns) and to maintain it. Specifically, self-control enables individuals to inhibit behaviors that may lead to divergence from balance (e.g., preventing overinvestment in either domain). Consistent with this idea, previous research has shown that self-control enables people to manage their competing motivations in such a way that people experience less goal conflict and greater fulfillment of multiple goals in their daily life (Galla \& Duckworth, 2015; Gillebaart \& DeRidder, 2015; Hofmann et al., 2014). Moreover, self-control may promote behaviors that help regain the balance when it is lost (e.g., redirecting attention and effort to the neglected domain). Certain situations (e.g. high professional demands) and individual factors (e.g., communal orientation) may trigger impulses that tempt people to overinvest in one domain 
over the other. Self-control can provide the ability to change those behavioral impulses and redirect them to re-establish balance. Thus, high self-control individuals should be more likely to experience personal-relational balance and should be less prone to experience either personal or relational imbalance.

There is growing evidence that self-control provides the ability to inhibit selfish impulses and behave in a pro-relationship manner instead (Pronk \& Righetti, 2015; Karremans, Pronk, Van der Wal, 2015). For example, self-control fosters derogation of attractive alternative partners (Pronk, Karremans, \& Wigboldus, 2011; Ritter, Karremans, \& Van Schie, 2010), constructive responses to destructive partner behaviors (Finkel \& Campbell, 2001), forgiveness in the face of a partner's transgressions (Pronk, Karremans, Overbeek, Vermulst, \& Wigboldus, 2010; Burnette, Davisson, Finkel, Van Tongeren, Hui, \& Hoyle, 2014), and some forms of sacrifice for the partner or relationship (Findley, Carvallo, \& Bartak, 2014; Pronk \& Karremans, 2014). However, although self-control provides the ability to behave in the interest of one's relationship, it does not necessarily need to be used as such. Given that self-control is a global ability that enables the self to bring its responses in line with one's standards (Baumeister et al., 2007), we argue that self-control may also promote self-interested behaviors when necessary. Consistent with this idea, researchers found that although self-control helps people to achieve their personal goals, it is not necessarily used to benefit close others (Cortes, Kammrath, Scholer, \& Peetz, 2014). Moreover, Righetti, Finkenauer, and Finkel (2013) found that in communal relationships, self-control reduces sacrificing one's own needs, to avoid neglecting personal concerns. Finally, Kammrath et al. (2015) found that self-control reduces communal actions toward one's partner in established relationships.

In the present work, for the first time, we propose that instead of self-control actively promoting either pro-relationship or pro-self behaviors, self-control may be used in the 
challenging task of trying to control one's optimal balance between personal and relational concerns. Self-control may provide the ability to bring thoughts, motivations, and behaviors in line with one's desired level of balance, and thus, we expect self-control to be positively related to experiencing personal-relational balance and negatively related to experiencing imbalance (i.e., overdedication to either personal or relational concerns). Moreover, extending our main focus to also consider broader outcomes on well-being, we propose that the ability to balance personal and relational concerns may be one of the mechanisms by which selfcontrol promotes personal and relationship well-being. This notion is rooted in research showing several benefits of self-control for personal and relationship well-being, including greater life satisfaction, psychological adjustment, relationship satisfaction, and dyadic adjustment (e.g., Hofmann et al., 2014; Tangney, Baumeister, \& Boone, 2004; Vohs et al., 2011), as well as in research showing the benefits of personal-relational balance for personal and relationship well-being (Kumashiro et al., 2008). Thus, self-control may help achieve personal and relationship well-being in part due to being able to successfully balance personal and relationship concerns.

\section{Research overview}

This paper presents a novel model in which we propose that self-control plays an important role in regulating personal-relational balance, which in turn leads to higher levels of both personal and relational well-being. In two studies of romantic couples ${ }^{2}$, employing daily diary procedures and laboratory assessments, we tested the hypothesis that self-control promotes personal-relational balance (i.e., experiencing higher levels of balance and lower levels of personal and relational imbalance). In both studies, we also tested whether personalrelational balance mediates the associations between self-control and personal and relationship well-being. 


\section{Study 1}

Study 1, conducted among a Dutch sample of romantic couples, employed a diary procedure which allowed us to capture everyday experiences of romantic couples while minimizing memory bias. We examined whether self-control is positively associated with daily experiences of personal-relational balance and negatively associated with both personal and relational imbalance. Furthermore, we examined whether personal-relational balance and imbalance mediate the associations between self-control and personal and relationship wellbeing.

\section{Method}

Participants. Participants were 125 heterosexual couples (and 1 individual) and 1 lesbian couple $(N=253)$, residing in The Netherlands. Participants' mean age was 23.33 years $(S D=3.65)$, and $64 \%$ were students. On average, couples were involved for 2.84 years $(S D=29.01$ months $)$, and 35\% lived together. The sample size was not specifically determined for the current research, because the data are derived from a larger project on romantic relationships. Originally, 130 couples participated, but one couple broke up before the diary procedure, and two couples and one individual did not follow instructions.

Measures and procedure. First, self-control was assessed during a laboratory session, using the 11-item Tangney self-control questionnaire (Tangney et al., 2004; "I have a hard time breaking habits"; $\alpha=.76$ ), scaled from 1 (do not agree at all) to 7 (agree completely). Additionally, the Stroop color-word task (Stroop, 1935) assessed response inhibition (an important aspect of self-control; e.g., Hofmann et al., 2012) ${ }^{3}$. In this task, participants indicated the color in which color-words were presented, which was either congruent or incongruent with the meaning of the color-words. Response latencies for congruent trials were subtracted from incongruent trial latencies, with higher latencies reflecting higher Stroop interference. At the end of the laboratory session, participants were instructed to start the 8- 
day diary procedure (using the SurveySignal application; Hofmann \& Patel, 2015). In general, participants responded to $87.6 \%$ of the daily surveys $(M=7.35$ out of 8 days). All items in the diary procedure were scaled from 0 (not at all) to 6 (very much), and were assessed with one item each to minimize participant fatigue and attrition (Bolger, Davis, \& Rafaeli, 2003).

During the laboratory session, participants were instructed with a PowerPoint presentation on the definition of personal-relational balance and imbalance. Personalrelational balance was explained as an overall feeling of satisfying both personal and relational goals and needs. Participants were instructed to indicate for each day of the diary procedure to which extent they felt like their personal and relational concerns were balanced (“My personal and relational needs were optimally balanced"). To assess personal imbalance, participants were asked to indicate to which extent they felt like they had been too immersed in personal goals and needs, at the expense of their relational concerns ("I mainly focused on my personal needs, at the expense of my relational needs"), and to assess relational imbalance, they were asked to indicate whether they felt like they were too immersed in relationship goals and needs, at the expense of their personal concerns ("I mainly focused on my relational needs, at the expense of my personal needs"). ${ }^{4}$ Life satisfaction ("My life is close to ideal") and stress ("I feel stressed") indicated personal well-being, and relationship satisfaction ("I feel satisfied with our relationship") indicated relationship well-being. See Supplemental Materials 1 for descriptive statistics and correlations between all variables.

\section{Results}

Multilevel-modeling, using random intercepts and fixed slopes, was used to take into account the occurrence of multiple measurement occasions (level 1) within participants (level 2) and the nesting of participants within couples (level 3; Raudenbush \& Bryk, 2002). This allowed us to examine individual differences while taking into account the within-person variability throughout the diary procedure (Bolger, Davis, \& Rafaeli, 2003). Personal- 
relational balance, personal imbalance, and relational imbalance (level 1 variables) were each separately regressed onto self-reported self-control and Stroop interference (level 2 variables). Participants' sex did not reliably moderate the effects; therefore dyads were treated as indistinguishable (Kenny, Kashy, \& Cook, 2006). To test for mediation, we used the Monte Carlo Method for Assessing Mediation (MCMAM), using unstandardized estimates. This simulation method shows $95 \%$ confidence intervals for the indirect effects using 20,000 simulations (Selig \& Preacher, 2008). ${ }^{5}$

Results of the separate multilevel modeling analyses revealed that both self-control and Stroop interference were significantly associated with personal-relational balance. However, neither self-control nor Stroop interference were significantly associated with personal and relational imbalance. ${ }^{6}$ See Table 1 for an overview of the main associations between self-control and personal-relational balance and imbalance.

Furthermore, self-control significantly predicted higher life satisfaction and lower stress, and personal-relational balance reliably mediated the associations between self-control and life satisfaction and stress, although these indirect effects were relatively small in magnitude. However, relationship satisfaction was not significantly predicted by self-control $(p=.424)$. Finally, Stroop task latencies were not significantly associated with life satisfaction $(p=.952)$, stress $(p=.933)$, and relationship satisfaction $(p=.310)$. See Table 2 for an overview of the associations between self-control and life satisfaction and stress. Also, see Supplemental Materials 2 for all direct associations of personal-relational balance, personal imbalance, and relational imbalance with well-being. 
Table 1.

Associations of self-control and Stroop interference with personal-relational balance, personal imbalance, and relational imbalance (Study 1)

\begin{tabular}{|c|c|c|c|c|c|}
\hline & $\beta$ & $95 \% \mathrm{CI}$ & $d f$ & $t$ & $p$ \\
\hline \multicolumn{6}{|l|}{ Self-control } \\
\hline Personal-relational balance & .11 & $.002, .22$ & 222 & 1.99 & .048 \\
\hline Personal imbalance & -.05 & $-.17, .08$ & 237 & -0.73 & .466 \\
\hline Relational imbalance & .001 & $-.12, .12$ & 243 & 0.02 & .983 \\
\hline \multicolumn{6}{|l|}{ Stroop interference } \\
\hline Personal-relational balance & -.14 & $-.25,-.03$ & 233 & -2.41 & .017 \\
\hline Personal imbalance & .04 & $-.08, .16$ & 244 & 0.61 & .540 \\
\hline Relational imbalance & .03 & $-.09, .15$ & 248 & 0.48 & .630 \\
\hline
\end{tabular}

Table 2.

Associations of self-control with life satisfaction and stress (Study 1)

\begin{tabular}{rcccccc}
\hline & $\beta$ & $S E$ & $95 \% \mathrm{CI}$ & $d f$ & $t$ & $p$ \\
\hline Life Satisfaction & & & & & & \\
Personal-relational Balance & .12 & .02 & $.09, .15$ & 1742 & 7.81 & $<.001$ \\
Self-control Total effect & .23 & .06 & $.11, .36$ & 215 & 3.78 & $<.001$ \\
Direct effect & .22 & .06 & $.10, .34$ & 213 & 3.71 & $<.001$ \\
Indirect effect & & & {$[.001, .03]$} & & & \\
\hline Stress & & & & & & \\
Personal-Relational Balance & -.09 & .02 & $-.13,-.05$ & 1822 & -4.57 & $<.001$ \\
Self-control Total effect & -.12 & .06 & $.24,-.004$ & 219 & -2.02 & .045 \\
$\quad$ Direct effect & -.11 & .06 & $-.23, .005$ & 219 & -1.88 & .061 \\
Indirect effect & & & {$[-.02,-.0004]$} & & & \\
\hline
\end{tabular}

Note. All results are obtained from mediation analyses, using unstandardized estimates.

Numbers between brackets are 95\% confidence intervals using the MCMAM to test the 
indirect effects of self-control on life satisfaction and stress mediated by personal-relational balance.

\section{Study 2}

Study 1 provided novel support for our hypothesis that self-control promotes personalrelational balance in daily life, which was additionally supported by Stroop interference, which may be regarded as a behavioral measurement of self-control. Also, the findings were largely consistent with the hypothesized mediation model, in which personal-relational balance may be one of the mechanisms by which self-control may affect personal well-being. However, Study 1 did not reveal a significant association between self-control and relationship well-being nor significant associations between self-control and personal and relational imbalance. Given that perceptions of imbalance may not occur on a daily basis, Study 2 examined general levels of personal-relational balance and imbalance across a wider timeframe.

\section{Method}

Participants. Participants were 149 romantic couples (145 heterosexual, 4 lesbian), and 4 individuals (whose partner did not respond; $N=302$ ), who resided in the USA. The data were taken from Time 1, 2, and 4 of a five-wave longitudinal study (separated by 6 months between each wave), in which measures relevant to this study were assessed. At Time 2, when the dependent variables were first assessed, participants' mean age was 25.83 years $(S D=$ $4.41)$, and $46 \%$ were students. On average, couples were involved for 3.79 years $(S D=25.81$ months), $74 \%$ were engaged or married, and $95 \%$ lived together. The sample size was determined as in Study 1. Originally, 159 couples (and 4 individuals) participated at Time 2, but ten couples did not complete Time 1's self-control assessment.

Measures and procedure. Self-control was measured during a laboratory session at Time 1, using the same scale as in Study 1 (Tangney et al., 2004; $\alpha=.77$ ), scaled from 0 (do 
not agree at all) to 8 (agree completely). At Time 2 and 4, participants received

questionnaires by mail, which assessed personal-relational balance and imbalance (Kumashiro et al., 2008) and personal and relationship well-being.

Participants' general levels of personal-relational balance and imbalance were assessed $(0=$ do not agree at all; $8=$ agree completely $)$, with two items assessing personal-relational balance (e.g., "I make both my relational needs and personal needs a major priority in life"; Time 2 and $4 \alpha \mathrm{s}=.83$ and .78), four items assessing personal imbalance (e.g., "I dedicate almost all of my time and resources to my personal needs and interests", and "I tend to neglect my relational needs and interests"; Time 2 and $4 \alpha \mathrm{s}=.78$ and .78$)$, and three items assessing relational imbalance (e.g., "I tend to make my relationship too much of a priority in my life", and "I tend to neglect my personal needs and interests"; Time 2 and $4 \alpha$ s $=.80$ and $.83) .^{7}$

Furthermore, personal well-being was measured with life satisfaction, subjective wellbeing, and psychological adjustment. Life satisfaction was assessed using the 5-item life satisfaction scale (Diener, Emmons, Larsen, \& Griffin, 1985; e.g., "I am satisfied with my life"; Time 2 and $4 \alpha \mathrm{s}=.89$ and .90), scaled from 0 (do not agree at all) to 8 (agree completely). Subjective well-being was assessed by asking participants to describe their life using ten items, on a 9-point scale with two anchors (e.g., boring-interesting; enjoyablemiserable, reverse coded; Campbell, Converse, \& Rodgers, 1976; Time 2 and $4 \alpha$ s $=.86$ and .85). Psychological adjustment was measured with a composite score of the 'depression' and 'anxiety' scales of the Brief Symptom Inventory (Derogatis, 1993), assessing the prevalence of psychological problems $(0=$ bothered me not at all; $8=$ bothered me extremely; Time 2 and $4 \alpha \mathrm{s}=.94$ and .95$)$. Scores were reversed so that higher scores reflected better psychological adjustment. 
Relationship well-being was measured using the 30-item Dyadic Adjustment Scale (Spanier, 1976), providing a general indication of couple functioning (e.g., "How often do you think things are going well between you and your partner?"), answered on a 6-point scale $(1=$ never, $6=$ all the time; Time 2 and $4 \alpha \mathrm{s}=.90$ and .91). A sum score was used in the analyses. Furthermore, the 10-item relationship satisfaction subscale of the DAS measured relationship satisfaction. For example, participants indicated the degree of happiness in their relationship $(1=$ extremely unhappy; $7=$ perfect; Time 2 and $4 \alpha \mathrm{s}=.81$ and .85$)$. See Supplemental Materials 1 for descriptive statistics and correlations between all variables.

\section{Results}

As in Study 1, multilevel-models with random intercepts and fixed slopes were used to take into account the occurrence of multiple measurement occasions within participants and the nesting of participants within couples (Raudenbush \& Bryk, 2002), allowing us to examine individual differences while taking into account within-person variability throughout two measurement waves (Time 2 and 4). Personal-relational balance, personal imbalance, and relational imbalance were each separately regressed onto trait self-control. Furthermore, we performed lagged analyses to examine whether earlier assessment of self-control (Time 1) would continue to predict later assessment of personal-relational balance and imbalance (Time 4), while controlling for the criterion level of personal-relational balance and imbalance in the previous year (Time 2).

Results from concurrent analyses revealed that self-control was positively associated with personal-relational balance, and negatively associated with personal and relational imbalance. ${ }^{8}$ Furthermore, lagged analyses showed a significant positive association between earlier self-control and later personal-relational balance, while controlling for earlier personalrelational balance. However, we did not find significant associations between earlier selfcontrol and later personal imbalance and relational imbalance. ${ }^{9}$ See Tables 3 and 4 for 
overviews of the concurrent and lagged associations of self-control with personal-relational balance, personal imbalance, and relational imbalance.

Table 3.

Concurrent associations of self-control with personal-relational balance, personal imbalance, and relational imbalance (Study 2)

\begin{tabular}{lccccc}
\hline & $\beta$ & $95 \% \mathrm{CI}$ & $d f$ & $t$ & $p$ \\
\hline Self-control & & & & & \\
$\quad$ Personal-relational balance & .38 & $.24, .52$ & 285 & 5.39 & $<.001$ \\
$\quad$ Personal imbalance & -.21 & $-.35,-.07$ & 289 & -2.88 & .004 \\
$\quad$ Relational imbalance & -.27 & $-.45,-.09$ & 296 & -3.02 & .003 \\
\hline
\end{tabular}

\section{Table 4.}

Lagged associations of self-control with personal-relational balance, personal imbalance, and relational imbalance (Study 2)

\begin{tabular}{lccccc}
\hline & $\beta$ & $95 \%$ CI & $d f$ & $t$ & $p$ \\
\hline Later personal-relational balance from & & & & & \\
$\quad$ Earlier personal-relational balance & .46 & $.27, .62$ & 204 & 4.68 & $<.001$ \\
$\quad$ Self-control & .22 & $.03, .41$ & 215 & 2.24 & .026 \\
Later personal imbalance from & & & & & $<.001$ \\
$\quad$ Earlier personal imbalance & .82 & $.65, .99$ & 213 & 9.47 & .886 \\
$\quad$ Self-control & -.01 & $-.18, .15$ & 211 & -0.14 & \\
Later relational imbalance from & & & & & \\
$\quad$ Earlier relational imbalance & .84 & $.64,1.04$ & 200 & 8.18 & $<.001$ \\
$\quad$ Self-control & -.04 & $-.25, .16$ & 210 & -0.43 & .669 \\
\hline Note. Associations of self-control with
\end{tabular}

Note. Associations of self-control with later personal-relational balance and later imbalance are obtained from lagged analyses, in which later (Time 4) personal-relational balance and imbalance were regressed onto earlier self-control (Time 1) while controlling for earlier (Time 2) balance and imbalance. 
Furthermore, as shown in Tables 5a to 5e, results of separate concurrent multilevel modeling analyses showed that self-control predicted higher life satisfaction, subjective wellbeing, psychological adjustment, dyadic adjustment, and relationship satisfaction. Moreover, separate tests of indirect effects showed that personal-relational balance, personal imbalance, and relational imbalance all reliably mediated the associations between self-control and all well-being indicators, although these indirect effects were relatively small in magnitude. See Supplemental Materials 2 for all direct associations of personal-relational balance, personal imbalance, and relational imbalance with well-being.

Table 5a.

Associations between self-control and life satisfaction (Study 2)

\begin{tabular}{rcccccc}
\hline Life satisfaction & $b$ & $S E$ & $95 \%$ CI & $d f$ & $t$ & $p$ \\
\hline Personal-relational Balance & .28 & .04 & $.21, .35$ & 454 & 7.96 & $<.001$ \\
Self-control Total effect & .35 & .06 & $.23, .46$ & 252 & 5.92 & $<.001$ \\
Direct effect & .26 & .06 & $.16, .37$ & 254 & 4.79 & $<.001$ \\
Indirect effect & & & {$[.05, .13]$} & & & \\
\hline Personal imbalance & -.121 & .04 & $-.20,-.04$ & 465 & -2.92 & .004 \\
Self-control Total effect & .35 & .06 & $.23, .46$ & 252 & 5.92 & $<.001$ \\
Direct effect & .32 & .06 & $.21, .44$ & 248 & 5.50 & $<.001$ \\
Indirect effect & & & {$[.004, .04]$} & & & $<.001$ \\
\hline Relational imbalance & -.15 & .03 & $-.22,-.09$ & 471 & 4.90 & $<.001$ \\
Self-control Total effect & .35 & .06 & $.23, .46$ & 252 & 5.92 & $<.001$ \\
Direct effect & .31 & .06 & $.20, .42$ & 246 & 5.36 & \\
Indirect effect & & & {$[.01, .06]$} & & &
\end{tabular}

Note. All results are obtained from mediation analyses, using unstandardized estimates.

Numbers between brackets are 95\% confidence intervals using the MCMAM to test the indirect effect of self-control on life satisfaction mediated by personal-relational balance and imbalance. 
Table 5b.

Associations between self-control and subjective well-being (Study 2)

\begin{tabular}{rcccccc}
\hline Subjective well-being & $b$ & $S E$ & $95 \%$ CI & $d f$ & $t$ & $p$ \\
\hline Personal-Relational Balance & .27 & .03 & $.22, .33$ & 485 & 9.46 & $<.001$ \\
Self-control Total effect & .22 & .05 & $.13, .32$ & 289 & 4.64 & $<.001$ \\
Direct effect & .14 & .04 & $.05, .23$ & 299 & 3.18 & .002 \\
Indirect effect & & & {$[.05, .13]$} & & & \\
\hline Personal imbalance & -.15 & .04 & $-.22,-.08$ & 502 & 4.27 & $<.001$ \\
Self-control Total effect & .22 & .05 & $.13, .32$ & 289 & 4.64 & $<.001$ \\
Direct effect & .21 & .05 & $.12, .30$ & 294 & 4.35 & $<.001$ \\
Indirect effect & & & {$[.01, .05]$} & & & $<.001$ \\
Relational imbalance & -.17 & .03 & $-.23,-.12$ & 504 & 6.69 & $<.001$ \\
Self-control Total effect & .22 & .05 & $.13, .32$ & 289 & 4.64 & $<.001$ \\
Direct effect & .19 & .05 & $.09, .28$ & 289 & 4.01 & \\
Indirect effect & & & {$[.01, .07]$} & & &
\end{tabular}

Note. All results are obtained from mediation analyses, using unstandardized estimates.

Numbers between brackets are 95\% confidence intervals using the MCMAM to test the indirect effect of self-control on subjective well-being mediated by personal-relational balance and imbalance. 
Table 5c.

Associations between self-control and psychological adjustment (Study 2)

\begin{tabular}{rcccccc}
\hline Psychological adjustment & $b$ & $S E$ & $95 \%$ CI & $d f$ & $t$ & $p$ \\
\hline Personal-Relational Balance & .19 & .03 & $.12, .25$ & 478 & 5.59 & $<.001$ \\
Self-control Total effect & .39 & .05 & $.28, .49$ & 290 & 7.15 & $<.001$ \\
Direct effect & .33 & .05 & $.23, .44$ & 292 & 6.31 & $<.001$ \\
Indirect effect & & & {$[.03, .09]$} & & & \\
\hline Personal imbalance & -.13 & .04 & $-.21,-.05$ & 498 & -3.34 & $<.001$ \\
Self-control Total effect & .39 & .05 & $.28, .49$ & 290 & 7.15 & $<.001$ \\
Direct effect & .37 & .05 & $.26, .47$ & 285 & 6.91 & $<.001$ \\
Indirect effect & & & {$[.01, .05]$} & & & $<.001$ \\
Relational imbalance & -.20 & .03 & $-.26,-.15$ & 500 & -7.03 & $<.001$ \\
Self-control Total effect & .39 & .05 & $.28, .49$ & 290 & 7.15 & $<.001$ \\
Direct effect & .34 & .05 & $.24, .44$ & 283 & 6.61 & \\
Indirect effect & & & {$[.02, .08]$} & & &
\end{tabular}

Note. All results are obtained from mediation analyses, using unstandardized estimates.

Numbers between brackets are 95\% confidence intervals using the MCMAM to test the indirect effect of self-control on psychological adjustment mediated by personal-relational balance and imbalance. 
Table 5d.

Associations between self-control and dyadic adjustment (Study 2)

\begin{tabular}{rcccccc}
\hline Dyadic adjustment & $b$ & $S E$ & $95 \%$ CI & $d f$ & $t$ & $p$ \\
\hline Personal-Relational Balance & 2.32 & .30 & $1.73,2.91$ & 467 & 7.82 & $<.001$ \\
Self-control Total effect & 2.08 & .46 & $1.16,2.99$ & 227 & 4.48 & $<.001$ \\
Direct effect & 1.43 & .45 & $.54,2.31$ & 244 & 3.16 & .002 \\
Indirect effect & & & {$[.43,1.08]$} & & & \\
\hline Personal imbalance & -2.39 & .33 & $-3.04,-1.73$ & 432 & -7.22 & $<.001$ \\
Self-control Total effect & 2.08 & .46 & $1.16,2.99$ & 227 & 4.48 & $<.001$ \\
Direct effect & 1.68 & .43 & $.82,2.53$ & 229 & 3.86 & $<.001$ \\
Indirect effect & & & {$[.12, .72]$} & & & \\
\hline Relational imbalance & -.74 & .27 & $-1.27,-.22$ & 462 & -2.79 & .006 \\
Self-control Total effect & 2.08 & .46 & $1.16,2.99$ & 227 & 4.48 & $<.001$ \\
Direct effect & 1.80 & .46 & $.90,2.70$ & 218 & 3.95 & $<.001$ \\
Indirect effect & & & {$[.03, .36]$} & & & \\
\hline
\end{tabular}

Note. All results are obtained from mediation analyses, using unstandardized estimates.

Numbers between brackets are 95\% confidence intervals using the MCMAM to test the indirect effect of self-control on dyadic adjustment mediated by personal-relational balance and imbalance. 
Table 5e.

Associations between self-control and relationship satisfaction (Study 2)

\begin{tabular}{rcccccc}
\hline Relationship satisfaction & $b$ & $S E$ & $95 \%$ CI & $d f$ & $t$ & $p$ \\
\hline Personal-Relational Balance & .08 & .01 & $.06, .10$ & 442 & 8.19 & $<.001$ \\
Self-control Total effect & .04 & .02 & $.01, .08$ & 238 & 2.71 & .007 \\
Direct effect & .02 & .02 & $.01, .05$ & 230 & 1.37 & .173 \\
Indirect effect & & & {$[.02, .04]$} & & & \\
\hline Personal imbalance & -.09 & .01 & $-.11,-.07$ & 411 & -8.22 & $<.001$ \\
Self-control Total effect & .04 & .02 & $.01, .08$ & 238 & 2.71 & .007 \\
Direct effect & .03 & .02 & $.001, .06$ & 218 & 2.02 & .045 \\
Indirect effect & & & {$[.01, .03]$} & & & \\
\hline Relational imbalance & -.03 & .01 & $-.05,-.02$ & 446 & -3.74 & $<.001$ \\
Self-control Total effect & .04 & .02 & $.01, .08$ & 238 & 2.71 & .007 \\
Direct effect & .03 & .02 & $.002, .07$ & 220 & 2.13 & .035 \\
Indirect effect & & & {$[.002, .02]$} & & & \\
\hline
\end{tabular}

Note. All results are obtained from mediation analyses, using unstandardized estimates.

Numbers between brackets are 95\% confidence intervals using the MCMAM to test the indirect effect of self-control on relationship satisfaction mediated by personal-relational balance and imbalance.

Moreover, as shown in Table 5f, results from separate lagged multilevel modeling analyses provided support for lagged indirect effects of self-control on each of the well-being indicators one year later, through later levels of personal-relational balance, controlling for earlier personal-relational balance and earlier well-being. Although some total effects of selfcontrol on later well-being were marginally significant (dyadic adjustment) or non-significant (subjective well-being, relationship satisfaction), later personal-relational balance reliably mediated associations of self-control with all later well-being indicators. At the same time, we should note that most of the indirect effects were relatively small in magnitude. 
Table 5f.

Lagged associations between self-control and all well-being indicators (Study 2)

\begin{tabular}{|c|c|c|c|c|c|c|}
\hline & $b$ & $S E$ & $95 \% \mathrm{CI}$ & $d f$ & $t$ & $p$ \\
\hline \multicolumn{7}{|l|}{ Life satisfaction } \\
\hline Later personal-relational balance & .27 & .05 & $.17, .37$ & 210 & 5.38 & $<.001$ \\
\hline Self-control Total effect & .20 & .06 & $.08, .32$ & 216 & 3.30 & .001 \\
\hline Direct effect & .14 & .06 & $.02, .26$ & 212 & 2.40 & .017 \\
\hline Indirect effect & & & {$[.01, .10]$} & & & \\
\hline \multicolumn{7}{|l|}{ Subjective well-being } \\
\hline Later personal-relational balance & .27 & .04 & $.19, .35$ & 212 & 6.10 & $<.001$ \\
\hline Self-control Total effect & .06 & .05 & $-.04, .16$ & 209 & 1.15 & .250 \\
\hline Direct effect & .01 & .05 & $-.09, .11$ & 212 & 0.28 & .782 \\
\hline Indirect effect & & & {$[.01, .10]$} & & & \\
\hline \multicolumn{7}{|l|}{ Psychological adjustment } \\
\hline Later personal-relational balance & .22 & .05 & $.12, .32$ & 214 & 4.52 & $<.001$ \\
\hline Self-control Total effect & .19 & .06 & $.07, .31$ & 214 & 3.17 & .002 \\
\hline Direct effect & .15 & .06 & $.03, .27$ & 213 & 2.56 & .011 \\
\hline Indirect effect & & & {$[.005, .08]$} & & & \\
\hline \multicolumn{7}{|l|}{ Dyadic adjustment } \\
\hline Later personal-relational balance & 1.97 & .42 & $1.14,2.80$ & 209 & 4.73 & $<.001$ \\
\hline Self-control Total effect & .83 & .47 & $-.10,1.76$ & 194 & 1.74 & .083 \\
\hline Direct effect & .67 & .48 & $-.28,1.62$ & 204 & 1.39 & .166 \\
\hline Indirect effect & & & {$[.04, .73]$} & & & \\
\hline \multicolumn{7}{|l|}{ Relationship satisfaction } \\
\hline Later personal-relational balance & .06 & .01 & $.03, .08$ & 195 & 4.08 & $<.001$ \\
\hline Self-control Total effect & .02 & .02 & $-.01, .06$ & 185 & 1.49 & .139 \\
\hline Direct effect & .02 & .02 & $-.01, .05$ & 187 & 1.03 & .305 \\
\hline Indirect effect & & & {$[.001, .02]$} & & & \\
\hline
\end{tabular}

Note. Total effects are obtained from analyses in which self-control predicted each of the well-being indicators one year later (Time 4), while controlling for earlier (Time 2) wellbeing. All other estimates are obtained from lagged mediation analyses, in which self-control predicted later well-being, while controlling for later personal-relational balance (the mediator), earlier personal-relational balance, and earlier well-being. Estimates are 
unstandardized, and numbers between brackets are $95 \%$ confidence intervals using the MCMAM to test the indirect effect of self-control on later well-being mediated by later personal-relational balance.

\section{Discussion}

With the present research, we challenged the predominant focus in the literature on the role of self-control in promoting mainly pro-relationship behaviors (e.g., Finkel \& Campbell, 2001; Findley et al., 2014; Pronk \& Karremans, 2014). Rather than focusing on self-control either promoting pro-relationship or pro-self dedication, our findings show that self-control promotes an optimal balance between personal and relationship concerns. Also, results partly supported our hypothesis that self-control prevents personal and relational imbalance (Study 2). Furthermore, we demonstrated that successfully maintaining personal-relational balance (Studies 1 and 2) and preventing personal and relational imbalance (Study 2) may be one of the mechanisms by which self-control can promote both personal well-being (e.g., higher life satisfaction, psychological adjustment, and lower stress) and relationship well-being (e.g., better couple functioning and higher relationship satisfaction; except for Study 1). Thus, these findings also show the importance of self-control in maintaining a healthy balance between personal and relational concerns, which in turn can promote personal and relationship wellbeing.

It was unexpected that self-control was not significantly associated with personal and relational imbalance in the daily diary study. We suggest the following possible explanations. One is that participants reported low levels of personal and relational imbalance on average (see Supplemental Materials 1), suggesting that in general participants did not experience problematic levels of imbalance, and thus there may have been less of a call for self-control. Another possibility is that efforts to repair personal or relational imbalance do not occur on a daily basis but over a longer period of time. 
In Study 2, self-control was in fact associated with lower personal and relational imbalance, presumably because in this study measures of balance and imbalance were tapping into general tendencies in attending to personal and relational concerns across a wider time frame. Study 2 complemented Study 1 also by including more interdependent couples (e.g., $95 \%$ of Study 2's couples lived together vs. $35 \%$ in Study 1). Perhaps in these more established relationships, partners are more likely to be concerned with maintaining personalrelational balance while being able to attend to both their personal and relational concerns. For example, partners may become even more reliant on self-control to prevent oneself from neglecting important personal goals and needs (Kammrath et al., 2015). A complementary possibility is that partners in highly interdependent relationships face more challenges: for example, demands from work may be more intense or the division of household chores more of an issue. Clearly, self-control and personal-relational balance are key ingredients to healthy relationships and well-being among highly interdependent and increasingly interdependent relationships. Greater insight into how partners address their personal and relational concerns may help us in understanding what it takes from partners to maintain healthy relationships, and to maintain or promote their own well-being.

A strength of the present research is that results were replicated in two different countries, The Netherlands and the USA, providing some evidence for the generalizability of the findings across Western populations. Furthermore, we employed a diary procedure to capture every day experiences of romantic couples, providing valuable insight into romantic couples' experiences in their daily lives. Findings also revealed that self-control significantly predicted personal-relational balance over time (Study 2). While this is not a demonstration of a causal relationship, it is consistent with the idea that self-control could play an important role in shaping personal-relational balance over time. Future research could complement these findings by using experimental procedures to examine how self-control minimizes personal 
and relational imbalance, such as by examining balance restoration efforts after experiencing imbalance. Also, future research could seek to generalize the current findings to other types of interpersonal relationships (e.g., friendships, family relations).

Our research shows that balancing personal and relational concerns requires selfcontrol; therefore, future research could explore how people can regulate this balance in ways that are less demanding of self-control, given that self-control can be temporarily depleted (Baumeister, Vohs, \& Tice, 2007). Also, as previous research has shown that self-control can be improved by extensive training (e.g., Baumeister, Gailliot, DeWall, \& Oaten, 2006; Baumeister, Vohs, \& Tice, 2007), therapists could make use of such training to increase people's ability to maintain a well-balanced life.

\section{Conclusion}

Romantic partners are inevitably challenged by how much time and effort they can dedicate to both their personal and relationship concerns: two domains that are both driven by strong motives to fulfill goals and needs within these domains. The present research has challenged the predominant research focus on self-control in fostering efforts to behave prorelationally. While most would agree that an extensive focus on personal interests poses a threat to relationships, there is also merit in the claim that there is something like "too much investment" in one's relationship. Although more research is needed, we close by concluding that self-control provides people with the ability to control a healthy balance between personal and relational interests and that this is one possible — and unrecognized - key to wellfunctioning relationships, as well as to well-functioning and happy people. 


\section{Footnotes}

${ }^{1}$ Previous work (Kumashiro et al., 2008) has used the term '(dis)equilibrium' to indicate (im)balance. Note that both labels refer to the same state.

${ }^{2}$ Data of Study 2 were partly used in Kumashiro et al. (2008), examining fluctuations in balance and accompanied well-being over time. The current research examined general levels of balance, and its relations to general levels of well-being, and importantly, the role of self-control in maintaining balance. Study 1 consists of newly collected data.

${ }^{3}$ Stroop interference and self-reported self-control were not significantly correlated $(p$ $>$.250). This is consistent with Toplak, West, and Stanovich (2013), showing correlations between self-reported self-control and executive functioning tasks to be non-significant or small at most.

${ }^{4}$ High levels of personal-relational balance and low levels of either personal or relational imbalance may be considered underlying the same construct. However, the three items did not yield an acceptable level of internal consistency $(\alpha=.39)$.

${ }^{5}$ Although within-person centering is usually recommended to assess the simple relationship between variables in diary or experience sampling procedures (see Bolger \& Laurenceau, 2013; Enders \& Tofighi, 2007), in the mediation analysis we sought to compare the total effect of self-control with the direct effect of self-control (which is a between-person variable assessed only at intake). Thus, to assess the reduction of the explained variance of self-control in the presence of the mediator, we did not within-person center personalrelational (im)balance, but examined the between participant variance of these variables. Mediation results, and direct daily association with personal and relational well-being, are similar when we within-person center personal-relational balance.

${ }^{6}$ Additionally, we controlled for relationship commitment and positive feelings toward the partner to ensure that our findings were not attributable to global positive 
relationship perceptions. All main effects of self-control on personal-relational balance and imbalance held when controlling for these relationship perceptions.

${ }^{7}$ In contrast to Study 1, the more general operationalized measures of personalrelational balance, personal imbalance, and relational imbalance reliably fit in an overall balance composite measure $(\alpha=.68)$. Indeed, self-control is significantly associated with overall balance $(\beta=.33,95 \% \mathrm{CI}=[.19, .47], t(280)=5.01, p<.001)$. Furthermore, overall balance similarly mediates associations between self-control and all well-being indicators.

${ }^{8}$ To ensure that our findings are not attributable to social desirable responding, we ran our key analyses controlling for this tendency (Paulhus, 1984) in Study 2. All the main effects of self-control on personal-relational balance and imbalance held when controlling for social desirable responding tendencies. Furthermore, as in Study 1, all main effects of self-control on personal-relational balance and imbalance held when controlling for relationship commitment.

${ }^{9}$ Personal-relational balance at Time 2 and Time 4 were moderately correlated $(r=$ .36), while personal imbalance and relational imbalance were highly correlated $(r=.56$ and 49 , respectively). The high associations between Time 2 and 4 levels of the criterion leaves less variance to be explained by other predictors. Furthermore, the attrition of 84 participants from Time 2 to Time 4 may have further challenged the test of this lagged model (i.e., less power to detect the effect and less variance to be explained over time). 


\section{References}

Aron, A., \& Aron, E. N. (1986). Love and the expansion of self: Understanding attraction and satisfaction. Washington, DC: Hemisphere.

Baumeister, R. F., Heatherton, T. F., \& Tice, D. M. (1994). Losing control: How and why people fail at self-regulation. San Diego, CA: Academic Press.

Baumeister, R. F., Gailliot, M., DeWall, C. N., \& Oaten, M. (2006). Self-regulation and personality: How interventions increase regulatory success, and how depletion moderates the effects of traits on behavior. Journal of Personality, 74, 1773-1801. doi: $10.1111 / \mathrm{j} .1467-6494.2006 .00428 . x$

Baumeister, R. F., \& Leary, M. R. (1995). The need to belong: Desire for interpersonal attachments as a fundamental human motivation. Psychological Bulletin, 117, 497-529. doi: 10.1037/0033-2909.117.3.497

Baumeister, R. F., Vohs, K. D., \& Tice, D. M. (2007). The strength model of self-control. Current Directions in Psychological Science, 16, 351-355. doi: 10.1111/j.14678721.2007.00534.x

Bolger, N., Davis, A., \& Rafaeli, E. (2003). Diary methods: Capturing life as it is lived. Annual Review of Psychology, 54, 579-616. doi: 10.1146/annurev.psych.54.101601.145030

Bolger, N., \& Laurenceau, J. P. (2013). Intensive longitudinal methods: An introduction to diary and experience sampling research. New York, NY: Guilford Press.

Burnette, J. L., Davisson, E. K., Finkel, E. J., Van Tongeren, D. R., Hui, C. M., \& Hoyle, R. H. (2014). Self-control and forgiveness: A meta-analytic review. Social Psychological and Personality Science, 5, 443-450. doi: 10.1177/1948550613502991

Campbell, A., Converse, P. E., \& Rodgers, W. L. (1976). The quality of American life: Perceptions, evaluations, and satisfactions. New York, NY: Russell Sage Foundation. 
Cortes, K., Kammrath, L. K., Scholer, A. A., \& Peetz, J. (2014). Self-regulating the effortful "social dos". Journal of Personality and Social Psychology, 106, 380-397. doi: $10.1037 / \mathrm{a} 0035188$

Deci, E. L., \& Ryan, R. M. (2000). The "what" and "why” of goal pursuits: Human needs and the self-determination of behavior. Psychological Inquiry, 11, 227268. doi: 10.1207/S15327965PLI1104_01

Derogatis, L. R. (1993). Brief Symptom Inventory: Administration, scoring, and procedures manual (4th ed.). Minneapolis, MN: NCS Pearson Assessments, Inc.

Diener, E., Emmons, R. A., Larsen, R. J., \& Griffin, S. (1985). The Satisfaction With Life Scale. Journal of Personality Assessment, 49, 71-75. doi: 10.1207/s15327752jpa4901_13

Enders, C. K., \& Tofighi, D. (2007). Centering predictor variables in cross-sectional multilevel models: A new look at an old issue. Psychological Methods, 12, 121-138. doi: $10.1037 / 1082-989 X .12 .2 .121$

Findley, M. B., Carvallo, M., \& Bartak, C. P. (2014). The effect of self-control on willingness to sacrifice in close relationships. Self and Identity, 13, 334-344. doi: $10.1080 / 15298868.2013 .826595$

Finkel, E. J., \& Campbell, W. K. (2001). Self-control and accommodation in close relationships: An interdependence analysis. Journal of Personality and Social Psychology, 81, 263-277. doi: 10.1037/0022-3514.81.2.263

Galla, B. M., \& Duckworth, A. L. (2015). More than resisting temptation: Beneficial habits mediate the relationship between self-control and positive life outcomes. Journal of Personality and Social Psychology, 109, 508-525. doi: 10.1037/pspp0000026

Gillebaart, M., \& Ridder, D. T. (2015). Effortless self-control: A novel perspective on 
response conflict strategies in trait self-control. Social and Personality Psychology Compass, 9, 88-99. doi: 10.1111/spc3.12160

Helgeson, V. S., \& Fritz, H. L. (1998). A theory of unmitigated communion. Personality and Social Psychology Review, 2, 173-183. doi: 10.1207/s15327957pspr0203_2

Hofmann, W., Luhmann, M., Fisher, R. R., Vohs, K. D., \& Baumeister, R. F. (2014). Yes, but are they happy? Effects of trait self-control on affective well-being and life satisfaction. Journal of Personality, 82, 265-277. doi: 10.1111/jopy.12050

Hofmann, W., \& Patel, P. V. (2015). SurveySignal: A convenient solution for experience sampling research using participants' own smartphones. Social Science Computer Review, 33, 235-253. doi: 10.1177/0894439314525117

Hofmann, W., Schmeichel, B. J., \& Baddeley, A. D. (2012). Executive functions and selfregulation. Trends in Cognitive Sciences, 16, 174-180. doi: 10.1016/j.tics.2012.01.006

Kammrath, L. K., Peetz, J., Hara, K., Demarco, A., Wood, K., Kirkconnell, J., Meirovich, H., \& Allen, T. (2015). It's a matter of time: The effect of depletion on communal action in romantic relationships is moderated by relationship length. Journal of Personality and Social Psychology, 109, 276-291. doi: 10.1037/pspi0000023

Kamp Dush, C. M., \& Amato, P. R. (2005). Consequences of relationship status and quality for subjective well-being. Journal of Social and Personal Relationships, 22, 607-627. doi: 10.1177/0265407505056438

Karremans, J. C., Pronk, T. M., \& Van der Wal, R. C. (2015). Executive control and relationship maintenance processes: An empirical overview and theoretical integration. Social and Personality Psychology Compass, 9, 333-347. doi: 10.1111/spc3.12177

Kenny, D. A., Kashy, D. A., \& Cook, W. L. (2006). Dyadic data analysis. New York, NY: Guilford Press.

Kiecolt-Glaser, J. K., \& Newton, T. L. (2001). Marriage and health: His and hers. 
Psychological Bulletin, 127, 472-503. doi: 10.1037/0033-2909.127.4.472

Kumashiro, M., Rusbult, C. E., \& Finkel, E. J. (2008). Navigating personal and relational concerns: The quest for equilibrium. Journal of Personality and Social Psychology, 95, 94-110. doi: 10.1037/0022-3514.95.1.94

Luchies, L. B., Finkel, E. J., McNulty, J. K., \& Kumashiro, M. (2010). The doormat effect: when forgiving erodes self-respect and self-concept clarity. Journal of Personality and Social Psychology, 98, 734-749. doi: 10.1037/a0017838

Patrick, H., Knee, C. R., Canevello, A., \& Lonsbary, C. (2007). The role of need fulfillment in relationship functioning and well-being: A self-determination theory perspective. Journal of Personality and Social Psychology, 92, 434-457. doi: $10.1037 / 0022-3514.92 .3 .434$

Paulhus, D. L. (1984). Two-component models of socially desirable responding. Journal of Personality and Social Psychology, 46, 598-609. doi: 10.1037/0022-3514.46.3.598

Pronk, T. M., Karremans, J. C., Overbeek, G., Vermulst, A. A., \& Wigboldus, D. H. J. (2010). What it takes to forgive: When and why executive functioning facilitates forgiveness. Journal of Personality and Social Psychology, 98, 119-131. doi: $10.1037 / \mathrm{a} 0017875$

Pronk, T. M., Karremans, J. C., \& Wigboldus, D. H. J. (2011). How can you resist? Executive control helps romantically involved individuals to stay faithful. Journal of Personality and Social Psychology, 100, 827-837. doi: 10.1037/a0021993

Righetti, F., Finkenauer, C., \& Finkel, E. (2013). Low self-control promotes the willingness to sacrifice in close relationships. Psychological Science, 24, 1533-1540. doi: $10.1177 / 0956797613475457$

Ritter, S. M., Karremans, J. C., \& Van Schie, H. T. (2010). The role of self-regulation in 
derogating attractive alternatives. Journal of Experimental Social Psychology, 46, 631637. doi:10.1016/j.jesp.2010.02.010

Raudenbush, S. W., \& Bryk, A. S. (2002). Hierarchical linear models: Applications and data analysis methods. Second edition . Newbury Park, CA: Sage.

Rusbult, C. E., Verette, J., Whitney, G. A., Slovik, L. F., \& Lipkus, I. (1991). Accommodation processes in close relationships: Theory and preliminary empirical evidence. Journal of Personality and Social Psychology, 60, 53-78. doi: $10.1037 / 0022-3514.60 .1 .53$

Selig, J. P., \& Preacher, K. J. (2008). Monte Carlo method for assessing mediation: An interactive tool for creating confidence intervals for indirect effects [Computer software]. Available from http://quantpsy.org/.

Spanier, G. B. (1976). Measuring dyadic adjustment: New scales for assessing the quality of marriage and similar dyads. Journal of Marriage and the Family, 38, 15-28. doi: $10.2307 / 350547$

Stroop, J. R. (1935). Studies of interference in serial verbal reactions. Journal of Experimental Psychology, 18, 643-662. doi: 10.1037/h0054651

Tangney, J. P., Baumeister, R. F., \& Boone, A. L. (2004). High self-control predicts good adjustment, less pathology, better grades, and interpersonal success. Journal of Personality, 72, 271-322. doi: 10.1111/j.0022-3506.2004.00263.x

Toplak, M. E., West, R. F., \& Stanovich, K. E. (2013). Practitioner Review: Do performancebased measures and ratings of executive function assess the same construct? Journal of Child Psychology and Psychiatry, 54, 131-143. doi: 10.1111/jcpp.12001

Van Lange, P. A. M., Rusbult, C. E., Drigotas, S. M., Arriaga, X. M., Witcher, B. S., \& Cox, C. L. (1997). Willingness to sacrifice in close relationships. Journal of Personality and Social Psychology, 72, 1373-1395. doi: 10.1037/0022- 
3514.72.6.1373

Vohs, K. D., Finkenauer, C., \& Baumeister, R. F. (2011). The sum of friends' and lovers' selfcontrol scores predicts relationship quality. Social Psychological and Personality

Science, 2, 138-145. doi: 10.1177/1948550610385710 